\title{
Pricing of pharmaceuticals is becoming a major challenge for health systems
}

\author{
Manufacturers using their market power to maximise profits results in prices that are unjustifiable \\ and unaffordable, argue Steven Morgan and colleagues
}



harmaceutical innovations over the past half century have enabled effective treatment and prevention of a wide range of illnesses. These advances were so important in modern healthcare that equitable access to them has been deemed to be a fundamental human right. ${ }^{1}$ Fulfilling that right creates tremendous social value but poses a significant policy challenge owing to its costs. Global expenditure on pharmaceuticals reached $\$ 1.135 \mathrm{tn}$ in 2017, up $56 \%$ from 2007 . $^{2}$

Although demand for medicines is one of the drivers of pharmaceutical expenditure, rising prices are a primary concern for health system managers because medicines are increasingly being priced at levels that appear "unfair." In this article, we review evidence that drug prices often exceed value for money and reasonable compensation for firms' investment in research. We argue that pharmaceutical pricing is a growing challenge for all countries, calling into question the sustainability of the systems that are supposed to drive pharmaceutical innovation.

\section{Innovation and market power}

To achieve social value from pharmaceutical innovations requires policies to promote the financing of research and development in areas of substantial unmet need

\section{KEY MESSAGES}

- Providing universal access to necessary medicines creates tremendous social value but poses a significant policy challenge owing to the costs involved

- Many medicines are being priced at levels unaffordable for payers while more than adequately compensating sellers for costs incurred or lacking justification in their benefits to health systems

- Governments, individually and collectively, must develop laws, policies, and institutional capacity that would prevent such "unfair" pricing while simultaneously providing access to innovations. Time limited market power through patents is one way of encouraging research investment while, eventually, allowing competition to drive down prices and thereby increase access. Patents strike a "fair" balance in ideal markets characterised by competition between new and old technologies serving the needs of fully informed consumers facing simple consumption trade-offs against well defined budget constraints.

Problems arise in the pharmaceutical sector because the ideal economic market seldom exists in healthcare, which can skew rewards for, and therefore investments in, innovation. The pharmaceutical sector can potentially abuse market power because of the inelasticity of demand for necessary medicines. Unlike consumers of ordinary goods, consumers of patented medicines-also known as patients with medical needs-may not be in a position to defer consumption until prices fall. Also, unlike ordinary consumers, patients are often insulated from the cost of the treatments owing to various forms of collective financing-most notably, public or private health insurance. Companies can exploit the vulnerability of patients and collective financing schemes by asking for prices that far exceed standard definitions of value for money. These inflated prices generate revenues that far exceed the costs of drug development.

\section{Concerning trends}

Prices of patented medicines

For both scientific and economic reasons, the pharmaceutical industry has placed increased emphasis on the development of specialty drugs in recent years. Over the past decade, for example, the average annual number of US Food and Drug Administration approvals of new oncology drugs increased $204 \%$ and average annual orphan drug approvals increased by $175 \% .^{34}$ In $2015,65 \%$ of new active substances first approved by the FDA, the
European Medicines Agency, and Health Canada were specialty drugs.

Together with the increased number of new specialty medicines, health systems are witnessing large increases in the cost for each patient treated with such drugs. For example, treatments for multiple sclerosis were priced in the US at $\$ 8000$ ( $£ 6400$; $€ 7100)$ to $\$ 11000$ a year in the mid1990s. In 2015 new treatments cost about $\$ 60000$ a year. ${ }^{6}$ Similarly, after adjusting for general inflation, the median monthly US price of new cancer treatments at the time of US FDA approval increased from just over $\$ 100$ in the 1960 s to over $\$ 10000$ in recent years. ${ }^{7}$ This trend in cancer prices has not been accompanied by evidence of commensurate improvements in treatment outcomes. $^{89}$

The prices of new treatments for rare diseases represent even less affordability. In the US in 2016, the median annual price for each patient a year treated with top selling orphan drugs was $\$ 83883$. This is 5.5 times the median annual cost for top selling non-orphan drugs. ${ }^{4}$ Some orphan drugs come at such high prices that they achieve "blockbuster drug" status despite being treatments for rare diseases. An example of this is ivacaftor, a treatment for certain subtypes of cystic fibrosis. It was priced in the US at about $\$ 300000$ per patient per year ${ }^{10}$ and has earned its manufacturer net global revenues of \$3.65bn from 2014 through 2018-with an additional \$4.68bn for related combination products over the same period. ${ }^{11}$ Eculizumab, used to treat paroxysmal nocturnal haemoglobinuria and atypical haemolytic uraemic syndrome, was priced in the US at roughly $\$ 400000$ per patient per year. It is expected to achieve over $\$ 5 \mathrm{bn}$ in annual sales by 2022. ${ }^{4}$

In many cases, the prices of new specialty drugs are well above traditional value-for-money thresholds defined by opportunity costs in health systems, beyond which coverage is unlikely. ${ }^{12}$ For example, the Canadian Agency for Drugs and Technologies in Health estimated the incremental cost for each quality adjusted 
life year gained using the combination drug lumacaftor/ivacaftor (Orkambi) to be \$C4 773615 in comparison with standard care. This is 50 to 100 times higher than thresholds beyond which public coverage is unlikely in Canada, even for treatment of rare diseases. ${ }^{13}$ Such list prices do not seem reasonable or "fair" in return for the health benefits provided, given the health gains achievable through alternative uses of the resources.

\section{Price secrecy and discrimination}

It might be argued that concern over high list prices is misplaced because manufacturers often give substantial discounts to institutional purchasers of medicines. These confidential discounts are now the norm among high income countries and can vary considerably across therapeutic areas and countries. ${ }^{14}$ Although they reduce final prices, the widespread use of confidential discounts is still a concern for health systems.

Confidential price discounts allow manufacturers to charge different payers different prices. Keeping final prices secret prevents everyone from demanding the lowest available price. If final prices negotiated confidentially reflect each health system's ability to pay, such a pricing scheme would allow manufacturers to serve more markets than might be possible with more transparent pricing. Secretive negotiations, however, are just as likely to result in the lowest prices for countries with the greatest negotiating power. This will not necessarily mean lower prices for poorer countries. Indeed, there is evidence that list prices of some medications are higher in absolute terms ${ }^{15}$ and as a percentage of average income, ${ }^{16}$ in low and middle income countries than in high income countries Secrecy makes it virtually impossible to guard against such inequity in final pricing.

Additionally, confidential negotiations often begin at list prices that far exceed conventional coverage thresholdssometimes by orders of magnitude. This indicates that manufactures intend to secure final prices that reach or exceed thresholds that would typically define the maximum value of a medicine to a health system. If this were not the intention, bargaining could begin at prices far closer to levels that can be justified by cost effectiveness. In this way they would more closely reflect the division of societal benefits of the innovation between innovator and health system. If every health system pays the maximum amount that it is willing to pay under circumstances of life or death price negotiations, without knowing that lower prices might be possible, there is a danger of creating excessive rewards for companies. It might also result in health system inefficiencies by displacing investments in higher value forms of care for patients. More transparent and consistent limits on the range of prices over which manufacturers may negotiate could make more medicines available to patients at prices more affordable to health systems, without discouraging investment in innovations of the greatest net social value.

\section{Revenues for patent holders}

Even when prices are within conventional cost effectiveness ranges, the total revenues of firms with patents and other forms of market protection may exceed levels that would seem reasonable or "fair." A prime example is sofosbuvir and related combination products manufactured by Gilead Sciences. Owing to exceptional efficacy, these new treatments for hepatitis $C$ could be viewed as cost effective for many patients, even at list prices that may appear very high. ${ }^{17}$ The effect on health system budgets and the revenues for the manufacturer nevertheless raise concerns.

Gilead's global sales of sofosbuvir and related combination products totalled \$59bn from 2014 through 2018. ${ }^{18}$ It has been estimated that the total cost of treating all patients with hepatitis $C$ at posted prices for sofosbuvir products would be equal to at least a tenth of the current annual cost for all medicines in 30 countries. ${ }^{19}$ Such extraordinary revenues for treating a single disease raise questions about affordability for health systems and the fairness of returns on research and development costs.

\section{Prices relative to research costs}

It might be argued that seemingly excessive pharmaceutical prices and revenues are fair today because development costs are higher. Manufacturers do not disclose their research and development costs, however, when claiming that high prices are needed to recoup investments. Instead, they often cite hypothetical average drug development costs based on opaque, self reported data. ${ }^{2021}$ In addition to the potential for bias in such data, average estimates are not specific to any company's case for the price of a particular drug. Furthermore, the trend towards developing more specialised drugs-particularly orphan drugs-implies that many new drugs are being approved based on smaller trials and, consequently, lower development costs. ${ }^{22}$
Cited costs of drug development also fail to acknowledge the critical role of public and non-profit financing of research and development. A recent study found that the US National Institutes of Health contributed an average of $\$ 839 \mathrm{~m}$ for basic or applied research for each of the 210 first-in-class drugs approved in the US between 2010 and $2016 .{ }^{23}$ Governments also make considerable indirect investments in drug development by tax deductions and tax credits. These can significantly lower manufacturer-borne development costs, particularly for orphan drugs. ${ }^{24}$

Policy makers and the public should also be wary about arguments that "acquisition costs" in the pharmaceutical sector represent investment in drug development. Much of the cost of acquiring firms that have developed promising new drugs-such as Gilead's \$11bn acquisition of Pharmasset in 2011-is a business investment in an intangible asset not an investment in research and development. ${ }^{25}$

Finally, a focus on drug development costs as a rationale for high prices for patented medicines misses a central point of the patent system. Patents are not backward looking policy tools meant to compensate firms for their previous investments. If they were, firms would have an incentive to waste resources during drug development, knowing that the system would compensate them in the end. Instead, patents are forward looking policy tools. They are meant to signal to firms that the potential return on innovation will be in proportion to the social value of the discovery, but never in excess of that value. This gives firms an incentive to choose research projects expected to generate a positive net social value after taking into account research costs, which they will also have an incentive to manage efficiently. In contrast, a reward structure that enables firms to charge prices exceeding societal value will over-reward the development of products that can command such prices, while diverting resources away from more productive uses within healthcare systems.

To maximise health benefits for populations and provide an incentive for valued innovations, health systems require policies to ensure that pharmaceutical prices never exceed comparative value for money, that returns for research investment are reasonable, and that price competition occurs as early as possible and is sustained. If such pricing would result in underinvestment in desirable pharmaceutical research and development, 
mechanisms to delink drug development costs from final pricing are required. ${ }^{26}$

\section{Prices of older drugs}

It is not simply patent monopolies that are driving up drug prices. Growth in off-patent pharmaceutical prices is also worrying. For example, a recent analysis found that most of the medicines on the WHO essential medicines list are sold in the UK and South Africa at prices significantly higher than those estimated from production costs; some generic medicines are priced at more than 100 times their estimated cost of production. ${ }^{27}$ Such prices suggest that market power is being exercised in ways inconsistent with the notion that off-patent pharmaceuticals should be available at prices close to the cost of production-the hallmark of ideal economic markets characterised by truly competitive pricing.

In recent years, the prices of off-patent drugs have also been growing rapidly in high income countries. ${ }^{28}$ When a manufacturer of an off-patent drug does not face competition and the treatment is essential, prices can be increased dramatically. This continues until a competitor enters the market. This was the case, for example, with Daraprim (pyrimethamine), an antiparasitic agent used to prevent or treat toxoplasmosis in immunocompromised patients. It has been available for about 60 years and went off patent in the 1970s. Turing Pharmaceuticals became the sole manufacturer of pyrimethamine in 2015 and chose to increase the price of a tablet from $\$ 13.50$ to $\$ 750$, a $5500 \%$ increase. ${ }^{29}$

\section{Conclusion}

There is evidence that pharmaceutical prices are often unfair. Many prices exceed affordability and value for money thresholds and are not justified by research and development costs. Such pricing is not required to bring desired innovations to market; it simply reflects manufacturers using their market power to maximise profits. Although it is tempting to blame industry alone for the outcomes, governments must prevent unfair pricing and barriers to access and distortions of innovation incentives.

Policies that extend intellectual property rights and limit price controls work against universal health and access to necessary medicines. Governments need to develop their capacities to redress such failings.

Contributors and sources: SGM is an economist who specialises in pharmaceutical policy. He is on the expert advisory committee for WHO's Fair Pricing Forum and previously served on the WHO'S
Consultative Expert Working Group on Research and Development: Financing and Coordination (CEWG). HSB is an Australian trained lawyer with a background in public health. She works on a range of health projects for federal and state health governments in Australia and worked as an intern in WHO headquarters in 2016. SM has conducted research for over two decades on policies to achieve more globally equitable innovation and access to medicines. She is a member of the expert advisory group for the WHO Fair Pricing Forum and leads research at the Global Health Centre of the Graduate Institute of Geneva.

Competing interests:We have read and understood BMJ policy on declaration of interests and have no relevant interests to declare.

Provenance and peer review: Commissioned; externally peer reviewed.

This article is part of a series proposed by WHO and commissioned by The BMJ. The BMJ retained full editorial control over external peer review, editing, and publication of these articles. Open access fees are funded by WHO.

Steven G Morgan, professor ${ }^{1}$

Hannah S Bathula, manager, EY health advisory ${ }^{2}$

Suerie Moon, director of research ${ }^{3,4}$

${ }^{1}$ School of Population and Public Health, University of British Columbia, Vancouver, Canada

${ }^{2}$ World Health Organization, Geneva, Switzerland

${ }^{3}$ Global Health Centre, Graduate Institute of

International and Development Studies, Geneva, Switzerland

${ }^{4}$ Harvard T H Chan School of Public Health, Boston,

MA, USA

Correspondence to: SMorgan

steve.morgan@ubc.ca

\section{(c) $\frac{(1)(8)}{\mathrm{Br} \text { Nc }}$ OPEN ACCESS}

This is an Open Access article distributed under the terms of the Creative Commons Attribution IGO License (https://creativecommons.org/licenses/ by-nc/3.0/igo/), which permits use, distribution, and reproduction for non-commercial purposes in any medium, provided the original work is properly cited.

\section{D) Check for updates}

1 World Health Organization. Access to essential medicines as part of the right to health. 2017; https://www.who.int/medicines/areas/human_ rights/en/. WHO, 2017.

2 IQVIA. 2018 and beyond: outlook and turning points. Parsippany, NJ: IQVIA Institute for Human Data Science, 2018. https://www.iqvia.com/institute/ reports/2018-and-beyond-outlook-and-turningpoints

3 CenterWatch. FDA approved drugs for oncology. 2018. https://www.centerwatch.com/druginformation/fda-approved-drugs/therapeuticarea/12/oncology.

4 EvaluatePharma. Orphan drug report 2017. 4th ed. 2017. http://info.evaluategroup.com/rs/607YGS-364/images/EPOD17.pdf

5 PMPRB. Meds entry watch, 2016. Ottawa: Patented Medicine Prices Review Board, 2018. http://www. pmprb-cepmb.gc.ca/view.asp?ccid=1374\&lang=en

6 Hartung DM, Bourdette DN, Ahmed SM, Whitham $\mathrm{RH}$. The cost of multiple sclerosis drugs in the US and the pharmaceutical industry: too big to fail? Neurology 2015;84:2185-92. doi:10.1212/ WNL.0000000000001608

7 Bach PB. Price \& value of cancer drug. Center for Health Policy and Outcomes at Memorial Sloan
Kettering Cancer Center, 2019. https://www.mskcc. org/research-programs/health-policy-outcomes/ cost-drugs

8 Cressman S, Browman GP, Hoch JS, Kovacic L, Peacock SJ. A time-trend economic analysis of cancer drug trials. Oncologist 2015;20:729-36. doi:10.1634/theoncologist.2014-0437

9 Gyawali B, Hey SP, Kesselheim AS. Assessment of the clinical benefit of cancer drugs receiving accelerated approval. JAMA Intern Med 2019. doi:10.1001/ jamainternmed.2019.0462

10 Cohen D, Raftery J. Paying twice: questions over high cost of cystic fibrosis drug developed with charitable funding. BMJ 2014;348:g1445. doi:10.1136/bmj. g1445

11 Business Wire. Vertex reports full-year and fourthquarter financial results. Vertex Pharmaceuticals Incorporated, 2019. https://www.businesswire.com/ news/home/20190205005917/en/Vertex-ReportsFull-Year-Fourth-Quarter-2018-Financial-Results

12 Woods B, Revill P, Sculpher M, Claxton K. Countrylevel cost-effectiveness thresholds: initial estimates and the need for further research. Value Health 2016;19:929-35. doi:10.1016/j. jval.2016.02.017

13 CADTH. CADTH Canadian Drug Expert Committee final recommendation: lumacaftor/ivacaftor. Ottawa: Canadian Agency for Drugs and Technologies in Health; 2016. https://www.cadth.ca/sites/default/ files/cdr/complete/SR0471_complete_OrkambiOct-28-16.pdf

14 Morgan SG, Vogler S, Wagner AK. Payers' experiences with confidential pharmaceutical price discounts: a survey of public and statutory health systems in North America, Europe, and Australasia. Health Policy 2017;121:354-62. doi:10.1016/j. healthpol.2017.02.002

15 Health Action International. Life-saving insulin largely unaffordable-a one day snapshot of the price of insulin across 60 countries. 2010. http://apps. who.int/medicinedocs/documents/s19160en/ s19160en.pdf

16 Goldstein DA, Clark J, Tu Y, et al. A global comparison of the cost of patented cancer drugs in relation to global differences in wealth. Oncotarget 2017;8:71548-55 . doi:10.18632/ oncotarget.17742

17 Chhatwal J, Kanwal F, Roberts MS, Dunn MA. Costeffectiveness and budget impact of hepatitis C virus treatment with sofosbuvir and ledipasvir in the United States. Ann Intern Med 2015;162:397-406. doi:10.7326/M14-1336

18 Gilead Sciences fourth quarter and full year financial results. Gilead Sciences, Inc, 2019. https://www. businesswire.com/news/home/20190204005678/ en/Gilead-Sciences-Announces-Fourth-Quarter-FullYear

19 Iyengar S, Tay-Teo K, Vogler S, et al. Prices, costs, and affordability of new medicines for hepatitis C in 30 countries: an economic analysis. PLoS Med 2016;13:e1002032. doi:10.1371/journal. pmed. 1002032

20 Morgan S, Grootendorst P, Lexchin J, Cunningham C, Greyson D. The cost of drug development: a systematic review. Health Policy 2011;100:4-17 doi:10.1016/j.healthpol.2010.12.002

21 Avorn J. The $\$ 2.6$ billion pill-methodologic and policy considerations. N Engl J Med 2015;372:1877 9. doi:10.1056/NEJMp1500848

22 Jayasundara K, Hollis A, Krahn M, Mamdani M, Hoch JS, Grootendorst P. Estimating the clinical cost of drug development for orphan versus non-orphan drugs. Orphanet J Rare Dis 2019;14:12. doi:10.1186/ s13023-018-0990-4

23 Galkina Cleary E, Beierlein JM, Khanuja NS, McNamee LM, Ledley FD. Contribution of NIH funding to new drug approvals 2010-2016. Proc Natl Acad Sci USA 2018;115:2329-34. doi:10.1073/ pnas.1715368115

24 Giannuzzi V, Conte R, Landi A, et al. Orphan medicinal products in Europe and United States to cover 
needs of patients with rare diseases: an increased common effort is to be foreseen. Orphanet J Rare Dis 2017;12:64. doi:10.1186/s13023-017-0617-1

25 Lopert R, Welch C. Costs of new treatments for hepatitis C infection. JAMA 2014;312:2168. doi:10.1001/jama.2014.14337

26 Røttingen J-A, Chamas C. A new deal for global health R\&D? The recommendations of the Consultative Expert Working Group on Research and
Development (CEWG). PLoS Med 2012:9:e1001219. doi:10.1371/journal.pmed.1001219

27 Hill AM, Barber MJ, Gotham D. Estimated

costs of production and potential prices for the WHO Essential Medicines List. BMJ Glob Health 2018;3:e000571. doi:10.1136/ bmjgh-2017-000571

28 Alpern JD, Song J, Stauffer WM. Essential medicines in the United States-why access is diminishing.
N Engl J Med 2016;374:1904-7. doi:10.1056/ NEJMp1601559

29 Tallapragada NP. Off-patent drugs at brandname prices: a puzzle for policymakers. / Law Biosci 2016;3:238-47. doi:10.1093/jlb/lsw008

Cite this as: BMJ 2020;368:14627 http://dx.doi.org/10.1136/bmj.l4627 